\title{
Acoustic mapping and classification of benthic habitat using unsupervised learning in artificial reef water
}

Article in Estuarine Coastal and Shelf Science · December 2016

DOI: 10.1016/j.ecss.2016.12.001

CITATIONS

0

4 authors, including:

\section{Chunlei Xia}

Pusan National University

21 PUBLICATIONS 71 CITATIONS

SEE PROFILE
READS

90

Some of the authors of this publication are also working on these related projects:

Project

A study on three-dimensional monitoring of individual behavior in fish group based on stereo vision View project

Developing greenhouse robots for pest sampling and control with minimal dose of pesticide View

Project
Hua Zhang

Chinese Academy of Sciences

54 PUBLICATIONS 435 CITATIONS

SEE PROFILE project 


\title{
Acoustic mapping and classification of benthic habitat using unsupervised learning in artificial reef water
}

\author{
Dong $\mathrm{Li}^{\mathrm{a}}{ }^{\mathrm{b}}$, Cheng Tang ${ }^{\mathrm{a},{ }^{*} \text {, Chunlei Xia }}{ }^{\mathrm{a}}$, Hua Zhang ${ }^{\mathrm{a},{ }^{* *}}$ \\ a Key Laboratory of Coastal Zone Environmental Processes and Ecological Remediation, Yantai Institute of Coastal Zone Research, Chinese Academy of \\ Sciences, Yantai, Shandong, China \\ ${ }^{\mathrm{b}}$ University of Chinese Academy of Sciences, Beijing, China
}

\section{A R T I C L E I N F O}

\section{Article history:}

Received 18 July 2016

Received in revised form

9 December 2016

Accepted 10 December 2016

Available online 12 December 2016

\section{Keywords:}

Artificial reef

Acoustic mapping

Automated classification

Multibeam echosounder

\begin{abstract}
A B S T R A C T
Artificial reefs (ARs) are effective means to maintain fishery resources and to restore ecological environment in coastal waters. ARs have been widely constructed along the Chinese coast. However, understanding of benthic habitats in the vicinity of ARs is limited, hindering effective fisheries and aquacultural management. Multibeam echosounder (MBES) is an advanced acoustic instrument capable of efficiently generating large-scale maps of benthic environments at fine resolutions. The objective of this study is to develop a technical approach to characterize, classify, and map shallow coastal areas with ARs using an MBES. An automated classification method is designed and tested to process bathymetric and backscatter data from MBES and transform the variables into simple, easily visualized maps. To reduce the redundancy in acoustic variables, a principal component analysis (PCA) is used to condense the highly collinear dataset. An acoustic benthic map of bottom sediments is classified using an iterative self-organizing data analysis technique (ISODATA). The approach is tested with MBES surveys in a $1.15 \mathrm{~km}^{2}$ fish farm with a high density of ARs off the Yantai coast in northern China. Using this method, 3 basic benthic habitats (sandy bottom, muddy sediments, and ARs) are distinguished. The results of the classification are validated using sediment samples and underwater surveys. Our study shows that the use of MBES is an effective method for acoustic mapping and classification of ARs.
\end{abstract}

() 2016 Published by Elsevier Ltd.

\section{Introduction}

Artificial reefs (ARs) are important for commercial fisheries, scuba diving tourism, ecosystem protection, and the control of illegal fishing (Seaman and Jensen, 2000; Yoon et al., 2016). AR habitats can improve marine biodiversity, create new food webs for commercial and recreational fishery, and reduce the impact of costal hazards (Bortone, 2015). The topographic complexity of the ARs provides shelter, food and protection for benthic organisms, especially for spawning. Studies have been conducted to estimate the efficacy of ARs for artisanal fisheries (Falace and Bressan, 2002; Tessier et al., 2014), to characterize patterns in fish colonization of ARs (Relini et al., 1994; Santos et al., 2010), to evaluate the role of ARs as part of marine protected area development (Brochier et al., 2015; Wilson et al., 2002), and to investigate the attraction-

\footnotetext{
* Corresponding author. 17 Chunhui Rd, Yantai, Shandong 264003, China.

** Corresponding author.

E-mail addresses: ctang@yic.ac.cn (C. Tang), hzhang@yic.ac.cn (H. Zhang).
}

concentration vs. production effects of ARs (Cresson et al., 2014b; Pickering and Whitmarsh, 1997). Most researches focused on the influence of ARs on aquatic ecosystems. However, there is a lack of AR habitats monitoring and, further, lack of detailed characterization of benthic surroundings of ARs. The construction of ARs is important for maintenance of offshore fishery resources (Schygulla and Peine, 2013), but it might also disturb marine environment and potentially have negative impacts on submarine habitats. Accurate spatial characterization of ARs and the delineation of their boundaries can provide important information on benthic environments for aquacultural industry. Mapping of ARs can assist recreational fishermen to build fishing platform, serve scuba divers to enjoy underwater scenery, help aquaculture industry to harvest economic benthic organisms such as sea cucumber, and support better management and more efficient AR deployment. In China, ARs have been built in selected areas near the coastline since the late 1970s. In the last few years, large-scale ARs (tens of square kilometers approximately $20 \mathrm{~km}$ offshore) were cultivated by aquaculture industries. A variety of materials were used in building ARs, including stone, concrete, and used vehicle tires. In addition, 
AR construction has been used to maintain offshore fishery resources and improve ecological conditions in marine conservation areas. However, few studies have examined the benthic environment within large-scale ARs.

In recent decades, acoustic techniques have been utilized to improve our ability to map the spatial characterization of benthic habitat in the presence of artificial structures (Kang et al., 2011). Acoustic habitat mapping has become a major tool for evaluating the status of coastal ecosystems. This technique is also commonly used in marine spatial planning, resource assessment and offshore engineering (Micallef et al., 2012). Traditional sampling methods can only provide a snapshot that covers a fraction of the seafloor area (Harper et al., 2010), while acoustic mapping technologies are capable of efficiently capturing images across large areas of the seabed (Huang et al., 2014). Advances in acoustic technologies, particularly multibeam echosounders (MBES), have enhanced our ability to characterize physical aspects of the benthic environment at fine scales (Brown and Blondel, 2009; Pickrill and Todd, 2003). Bathymetry data, together with acoustic backscatter data, depict the compositional characteristics of the seafloor surface and can provide important insights into the distribution and complexity of benthic habitats. Conventionally, MBES data sets of seabed geological features have been manually interpreted by experts or using simplified substrate classification methods developed for single beam echosounder. Recently developed quantitative computational techniques can transform spatially complex bathymetric and backscatter data of large areas into simple, easily visualized maps that provide the end users with abundant information (Micallef et al., 2012). Driven by the advances in objective classification algorithms, a variety of automated methods have been developed and tested (Brown et al., 2011). These approaches fall into two categories: unsupervised or supervised classification (Stephens and Diesing, 2014). Typical unsupervised methods consist of clustering techniques (e.g., k-means and ISODATA) that classify regularities in data sets into seabed acoustic classes (Brown and Collier, 2008; McGonigle et al., 2009). Supervised classification techniques (e.g., artificial neural networks and support vector machines) use ground-truth data to develop a predictive model (Hasan et al., 2012; Huang et al., 2014; Stephens and Diesing, 2014). The main difference between the two classification methods is whether there are enough training samples.

To our knowledge, technical approach has not been established for mapping and classification of AR substrate using MBES. The aim of this study is to develop and evaluate quantitative method to map ARs and surrounding habitats in coastal waters using multibeam acoustic data. An unsupervised method was developed to divide MBES data sets into seabed habitat classes and validated with ground-truth samples collected near large-scale ARs in Yantai, China. This automatic classification technology may help stakeholders, such as fisheries managers, recreational fishermen or scuba divers, in managing benthic habitat of coastal water.

\section{Materials and methods}

\subsection{Study area}

The survey area is located between $37^{\circ} 27^{\prime} \mathrm{N}, 121^{\circ} 45^{\prime} \mathrm{E}$ and $37^{\circ} 29^{\prime} \mathrm{N}, 121^{\circ} 48^{\prime} \mathrm{E}$, in the northern Shandong Province, one of the most productive marine fishing grounds in China. The survey covered an area approximately $10 \mathrm{~km}^{2}$ (Fig. 1). The hydrodynamics of this region is dominated by regular semidiurnal tidal currents. The Yellow Sea Warm Current (YSWC) transport from the East China Sea to the Yellow Sea carries heat flux into this region during winter, resulting in relatively high temperature and salinity (Zhang et al., 2008). The Yellow Sea Coastal Current (YSCC) is also a major current contributing to the transportation of materials (Yuan et al.,

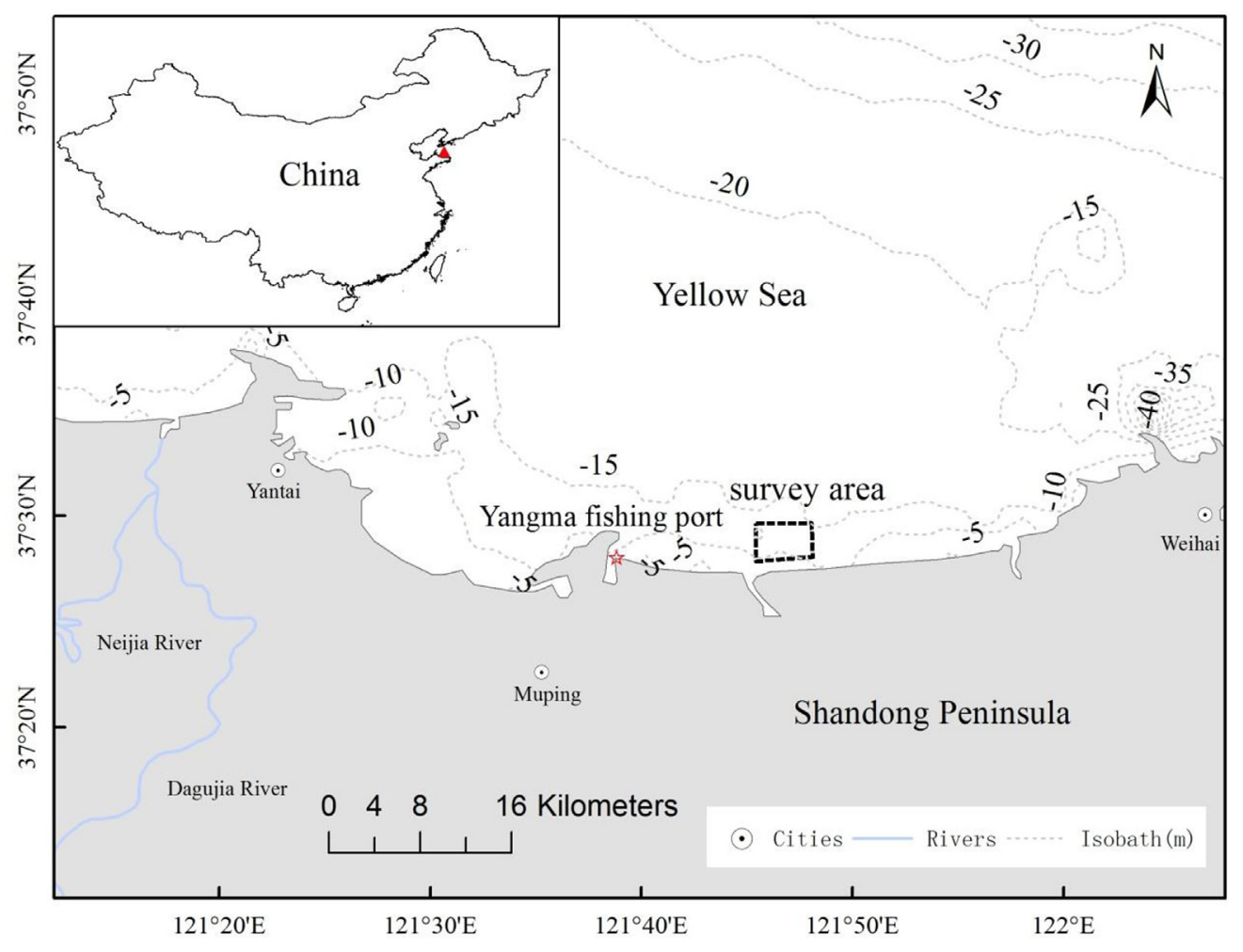

Fig. 1. Location of the survey area in the northern Shandong coastal waters of China. 
2008). The seabed is primarily composed of sandy and muddy sediments that are rich in nutrients and sustain productive fishing grounds. The area was planned to build ecological aqua farm named Oriental Ocean in 2011. As part of the aqua farm project, local companies have constructed different types of ARs (concrete blocks and stones) in this region to provide protection from trawling, additional food supplies and spawning substrate to improve survival and growth rates of benthic organisms, especially economically important sea cucumbers. Scarce information has been collected on the habitat complexity of the region, despite its importance in supporting productive commercial fisheries and tourism. Detailed topographic data, sediment type, and habitat properties were not available in open publications. A typical area (approximately $1.15 \mathrm{~km}^{2}$ ) in the southern part of the surveyed region was chosen to be the study area for method development.

\subsection{Data collection}

\subsubsection{Acoustic survey}

A bathymetric survey was conducted using an MBES (Sonic 2024; R2Sonic, LLC., U.S.) from August 28th to 31st in 2015. The multibeam transducer was mounted on the port side of the investigating fishing boat $(21 \mathrm{~m}$ in length, $4.5 \mathrm{~m}$ in width, and draught of $1.5 \mathrm{~m}$ ). The average ship speed was approximately 6 knots. The ultrasonic beam widths parallel and orthogonal to the direction of travel were within $1^{\circ}$ of each other, and the sonar frequency was set to $400 \mathrm{kHz}$. This system produces 256 beams equiangularly arrayed over an arc of $130^{\circ}$ and operates by ensonifying a narrow strip of the seafloor across the track to detect bottom echoes with swath width more than 4 times water depth. The navigation system used was the Differential Global Positioning System (DGPS, Hemisphere, Inc., Canada), with Octans IV gyrocompass and motion sensor (iXBlue, France), which provided submeter and $0.01^{\circ}$ accuracy for heave, roll and pitch accuracy. Realtime sound speed, which incorporates the sounds from different angles simultaneously, was measured using a sound velocity sensor (Minos SVP, AMLTM) that was installed near the transducers for beam steering. Data logging, real-time quality control, display and navigation were conducted using the QINSy v8.1 (QPS, Netherlands). The sound velocity of the ocean was measured during data acquisition every $2-3 \mathrm{~h}$ by using the sound velocity profiler
(Minos SVP, AML ${ }^{\mathrm{TM}}$ ) in different depth and was used to correct for the effects of sonar beam refraction caused by changes in water density. Tide gauge data were measured with an RBR pressure sensor in the nearest harbor (Yangma fishing port, about $10 \mathrm{~km}$ from the survey area, Fig. 1) and later corrected using RTK GPS transformations. During installation of the system, the relative positions of the multibeam system (i.e., the transducer, the DGPS and the motion sensor) were measured to correct for the postprocessing of the data. The survey lines (spacing $40 \mathrm{~m}$ ) were run roughly parallel to the coast with an overlap of $10-50 \%$ between adjacent swaths, which varied with the water depth. The multibeam transducer with a maximum frequency of $60 \mathrm{~Hz}$ automatically adjusted emission frequency according to water depth. Acoustic backscatter data was collected simultaneously and processed with TruePix ${ }^{\mathrm{TM}}$ into a single continuous times series record.

\subsubsection{Ground-truth survey}

Sediment samples were collected from 5 stations inside the study area using a Van Veen grab after the survey. The samples were used to identify the composition of the bottom sediments and to calibrate acoustic interpretations. Positional information was determined by DGPS, and each sample was described and photographed on site. The sediment samples were cleaned with hydrogen peroxide solution and distilled water and were analyzed for grain size distribution using a Mastersizer 2000 Laser Particle Size Analyzer (Malvern, U.K.). Grain size fractions were classified according to the median value and Udden-Wentworth scale. The gravel, sand and silt fractions as a percentage of the total sample weight were also calculated and were interpreted based on the following scale: gravel fraction $(\varphi<-1)$, sand fraction $(-1<\varphi<4)$, and silt fraction $(\varphi>4)$ (where grain size scale $\varphi=-\log _{2} D$, and $D$ is particle size $(\mathrm{mm})$ ). Ground-truth data were also obtained by scuba diving. An underwater camera was used to obtain video and photographic evidence of the seabed habitat at 3 sites. These data were included in the overall habitat descriptions as qualitative evidence. The site locations are shown in Fig. 2a.

\subsection{Data and methods}

\subsubsection{Acoustic derivative data}

All acoustic data was processed before further analysis by
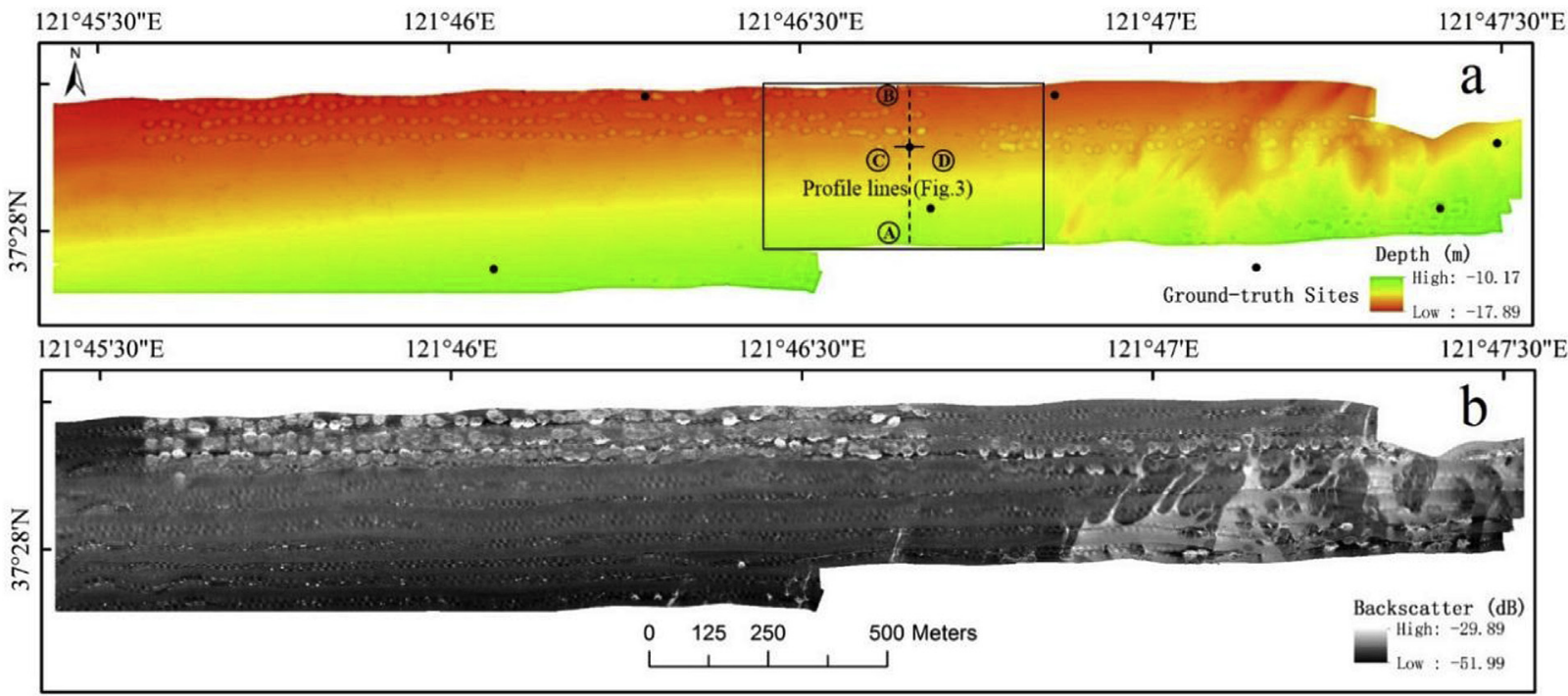

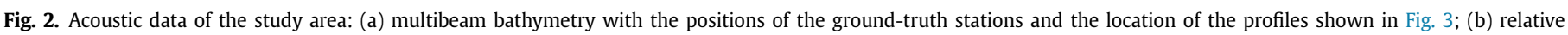
backscatter intensity. 
manually identifying and removing data spikes from beam profile. Processing of the raw bathymetry data included the following steps: correction for sound velocity variation through the water column, correction for tide variation at various water depths, filtering of motion sensor information, and removal of data outliers (Huang et al., 2014). Processing of the raw backscatter data involved correcting for transmission loss and ensonification area, removal of the system implemented model and angular dependence (Hill et al., 2014). Depth profiles which perpendicular to the shoreline and across ARs are shown in Figs. 2a, 3a,b and c, exhibiting obvious relief change. The cumulative frequency distribution curve for the slope gradient values across the study area is plotted in Fig. 3d. The data were gridded into cells at $0.5 \mathrm{~m}$ per pixel at full coverage based on the quality of raw data. This resolution could meet the requirements of ARs management and subsequent classification.

The spatial and physical gradients of seafloor, including reef topography and texture were reflected by MBES-derived variables (Hill et al., 2014; Stephens and Diesing, 2014). A suite of acoustic derived datasets was processed using ArcGISTM for further characterization of benthic habitats. The choice of secondary bathymetric variables was based on previously published studies (Brown et al., 2012; Hill et al., 2014; Huang et al., 2014; Ismail et al., 2015). These variables are valid indicators of substrate type and well represent variation in seafloor characteristics (Table 1). A stack layer of all 9 variables was generated for further analyses.

\subsubsection{Principal component analysis}

Principal component analysis (PCA) is a standard mathematical tool commonly used to condense a highly collinear dataset prior to clustering (McGonigle et al., 2009). PCA reveals the internal structure of the data in a way that best explains the variance in the data. It has been widely used in seabed classification to reduce data redundancy, especially for acoustic variables derived from multibeam bathymetry and backscatter data (Ismail et al., 2015). PCA is used to calculate a covariance matrix and transform the data set into a number of spatial principal components (PCs). Generally, the first three or four PCs of the resulting data set represented most of the total variance. Each of the 9 variables was normalized into a pixel with a value between 0 and 1 from their original data value for analysis. Following the Kaiser-Harris criterion, the analysis is limited to those PCs that have eigenvalues larger than 1, because they explain more variance than is contained in an original variable (Ismail et al., 2015).

\subsubsection{Unsupervised learning method}

Unsupervised clustering algorithms are fundamental tools in image processing for geoscience and remote sensing applications (Memarsadeghi et al., 2007). The iterative self-organizing data analysis technique (ISODATA) is a widely used classification methods (Micallef et al., 2007) that approximate the natural construction of a multidimensional dataset by iteratively passing it through defining classes to minimize pixel separation distance (D) and sum of squared error (SSE) (Ball and Hall, 1967; Jones et al., 2014).

$D=\sqrt{(x-\bar{x})^{2}+(y-\bar{y})^{2}}$

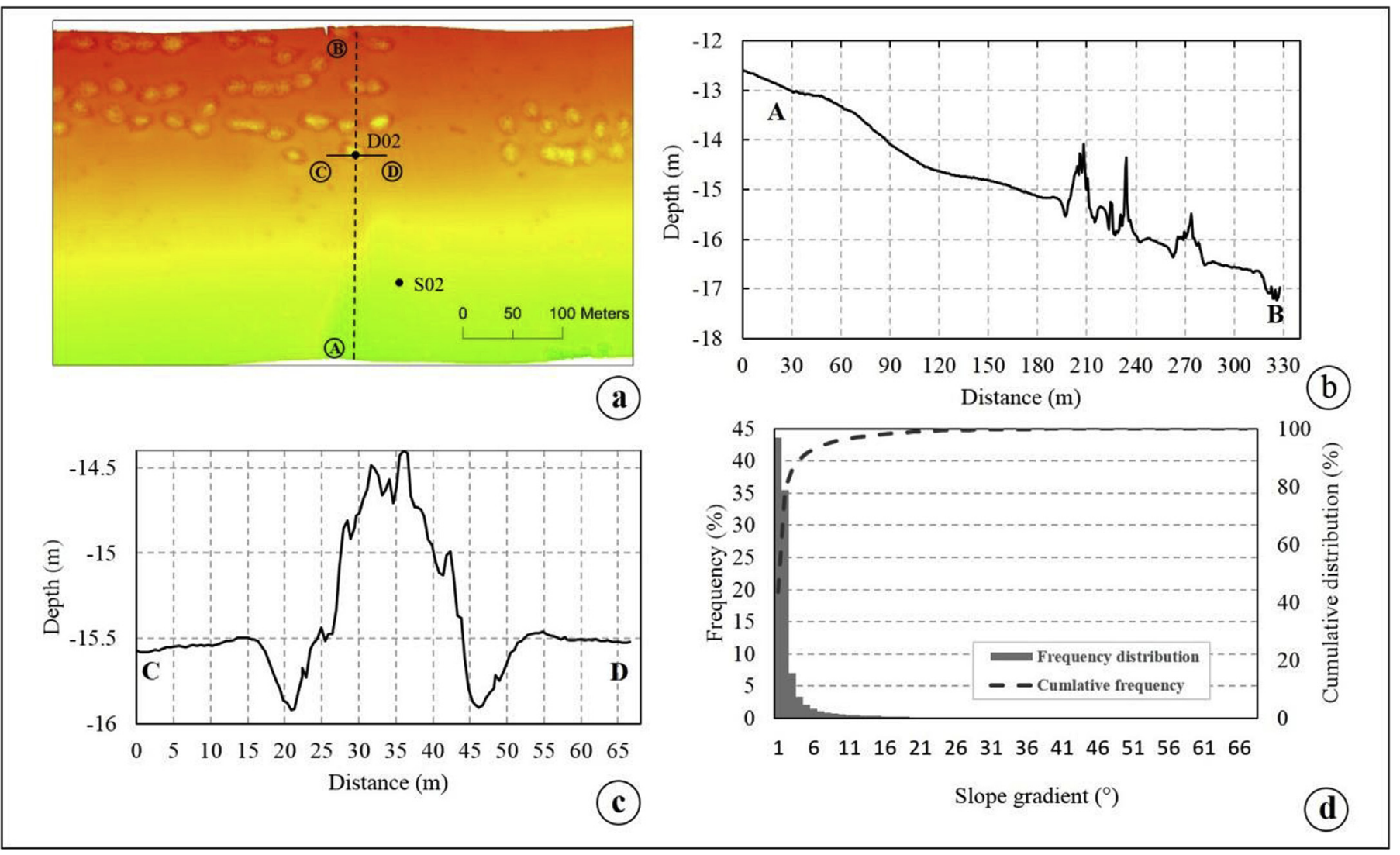

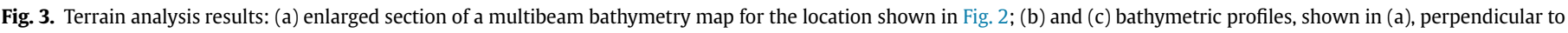
the shoreline and across ARs; (d) frequency distribution histogram and cumulative frequency distribution curve for slope gradient values across the study area. 
Table 1

Multibeam sonar derivative data.

\begin{tabular}{|c|c|c|}
\hline Data & Variable description ( $3 \times 3$ pixel analysis extent unless specified below) & Represents \\
\hline Backscatter & $\begin{array}{l}\text { Backscatter intensity is a function of the absorption and scattering of water and seabed interface, the angle of } \\
\text { incidence and the seafloor topography (Moustier and Matsumoto, 1993). }\end{array}$ & $\begin{array}{l}\text { Hardness and roughness of the } \\
\text { seafloor, habitat complexity }\end{array}$ \\
\hline Bathymetry & Depth (negative elevation) of a plane passing through the closest grid point. & $\begin{array}{l}\text { Detailed spatial variation of the } \\
\text { seafloor terrain }\end{array}$ \\
\hline Slope & $\begin{array}{l}\text { Maximum rate of change in elevation between each cell and the cells in its analysis neighborhood (degrees from } \\
\text { horizontal) (Ismail et al., 2015). }\end{array}$ & Water flow, shading \\
\hline $\begin{array}{l}\text { Benthic Position } \\
\text { Index (BPI) }\end{array}$ & $\begin{array}{l}\text { Measures of a location in the overall landscape; calculated by comparing the elevation of a cell with the mean } \\
\text { elevation of surrounding cells by a user-defined analysis extent. Locations that are higher than their surroundings } \\
\text { will have positive values, while areas that are lower will have negative values. Flat areas have values closer to zero } \\
\text { (Wilson et al., 2007). A fine-scale BPI was generated (inner radius = 10; outer radius }=20 \text {; scale factor }=200 \text { ). }\end{array}$ & Shading, water flow \\
\hline $\begin{array}{l}\text { Northness }=\cos \\
\quad \text { (aspect) }\end{array}$ & Deviation of aspect from $0^{\circ}$. Describes the orientation of slope. Indices provide continuous measure $(-1$ to +1$)$. & $\begin{array}{l}\text { Exposure to prevailing swell, } \\
\text { currents }\end{array}$ \\
\hline $\begin{array}{l}\text { Eastness }=\sin \\
\quad \text { (aspect) }\end{array}$ & Deviation of aspect from $90^{\circ}$. Describes the orientation of slope. Indices provide continuous measure $(-1$ to +1$)$. & $\begin{array}{l}\text { Exposure to prevailing swell, } \\
\text { currents }\end{array}$ \\
\hline $\begin{array}{l}\text { Terrain Ruggedness } \\
\quad \text { Index (TRI) }\end{array}$ & $\begin{array}{l}\text { A measure of the local variation in seabed terrain about a central pixel. The TRI value is calculated by comparing a } \\
\text { central pixel with its neighbors, taking the absolute values of the differences, and averaging the result (Muller and } \\
\text { Eagles, 2007). }\end{array}$ & $\begin{array}{l}\text { The variability or complexity of } \\
\text { the terrain }\end{array}$ \\
\hline $\begin{array}{l}\text { Topographic Relief } \\
\text { (TR) }\end{array}$ & The difference in elevation of a landform from the lowest point to the highest point. & $\begin{array}{l}\text { The variability or complexity of } \\
\text { the terrain }\end{array}$ \\
\hline Rugosity & $\begin{array}{l}\text { The roughness of a surface. This is calculated by obtaining the ratio between planer surface area and curved surface } \\
\text { area (Lundblad et al., 2006). }\end{array}$ & Habitat complexity, water flow \\
\hline
\end{tabular}

SSE $=\sum_{i=1}^{n}(x-\bar{x})^{2}$

where $(x, y)$ represents the pixel vector, $(\bar{x}, \bar{y})$ represents the cluster mean vector, and $n$ is the number of pixels points within the cluster.

The ISODATA clustering method uses the minimum distance formula to form clusters. It begins with an arbitrary value of cluster means, and as each time the clustering repeats, these cluster means are recalculated. The new cluster means are used for the next iteration. The ISODATA utility repeats the clustering of the image until either a maximum number of iterations have been performed, or a maximum percentage of unchanged pixels have been reached between two iterations (Adediran et al., 2004). This method makes a large number of passes through the dataset until specified results are obtained. The ISODATA algorithm is particularly powerful when little is known about the data prior to classification as it makes no assumptions on the underlying probability distribution of the datasets (Wu et al., 2007).

The ISODATA clustering method was applied to the analysis of MBES data using calculated PCs. Based on preliminary analysis and on-site survey data, ISODATA algorithm was executed with possible classes of 5,4 , and 3 , maximal iteration of 50 , minimum pixel number in a valid class of 20 , and sampling interval of 10 . Analysis result showed that no more than 3 classes could be categorized due to similarity of the acoustic derivative data. The output was a digital thematic map with each cluster represented by different classes.

\section{Results}

\subsection{Terrain and multivariate statistical analysis}

The bathymetry of the study area exhibited a depth ranged from -10.17 to $-17.89 \mathrm{~m}$ (Fig. 2a), and the backscatter intensity ranged from -29.89 to $-51.99 \mathrm{~dB}$ (Fig. 2b). The cumulative frequency distribution of the slope gradient showed that approximately $80 \%$ of the study area has a slope gradient under $2^{\circ}$, while $44 \%$ of the study area has a slope gradient under $1^{\circ}$ (Fig. $3 \mathrm{~d}$ ). The multibeam data and the secondary products clearly illustrate seabed physical properties and provide detailed morphology and sediment characterization of large-scale AR. The BPI was shown to be a useful indicator for differentiating large-scale ARs from sediment (Fig. 4b). Values of the slope, TRI, TR and rugosity were low in the sand and mud deposit sediments and high around the ARs (Fig. 4a, e, f and g). Eastness and northness provide information on the exposure of any given area to water current in these directions, which may be important in shaping habitat and colonization (Wilson et al., 2007). Some unconsolidated sediment boundaries had a smooth shape because of the hydrodynamic effects (Fig. 4c and $\mathrm{d}$ ).

Some variables, like slope, TRI, TR and rugosity, are strongly correlated as shown in Supplementary table. To reduce the redundancy in the dataset, PCA was conducted using the 9 variables and the first three principal components with eigenvalues $>1$ were retained for further analyses. The rotated component matrix of factor loadings explained the correlation between the rotated PCs and the original variables (Table 2). Each of the variables is represented by a vector in Fig. 5, and the length and direction of the vector indicate their contributions to the PCs. The variables that drive the PCA are eastness, bathymetry and backscatter (Fig. 5).

\subsection{Artificial reef area maps}

Fig. 6A shows an RGB false-color synthetic image of the three PCs. The thematic map generated using ISODATA is shown in Fig. 6B. The correspondence between the ISODATA classes and the pixels with three PCs is plotted in Fig. 7. The utilization of multibeam sonar derivative data and ground-truth data allowed us to determinate broad substrate categories derived from the ISODATA classification technique. The study area can be classified into 3 groups. Class 1, accounting for approximately $4.94 \times 10^{5} \mathrm{~m}^{2}$ (or $44.09 \%$ ) of the map, represented smooth sandy sediments that were primarily located in the southern portion of the study area, whereas class 2 represented flat muddy sediments and accounted for approximately $5.30 \times 10^{5} \mathrm{~m}^{2}$ (or $47.35 \%$ ) of the northern portion of the study area. The deposits were identified by collecting samples from the seafloor (Fig. $6 a$ and b). Some of the sediments were rippled due to regional hydrodynamics; the smooth shape could be distinguished in the cluster map. Some stones sporadically scattered in the sand and mud sediment could be identified in the classification map. ARs, which comprised approximately $9.59 \times 10^{4} \mathrm{~m}^{2}$ (or $8.56 \%$ ) of the study area, could be clearly distinguished in the map as class 3 . The majority of the ARs were in 


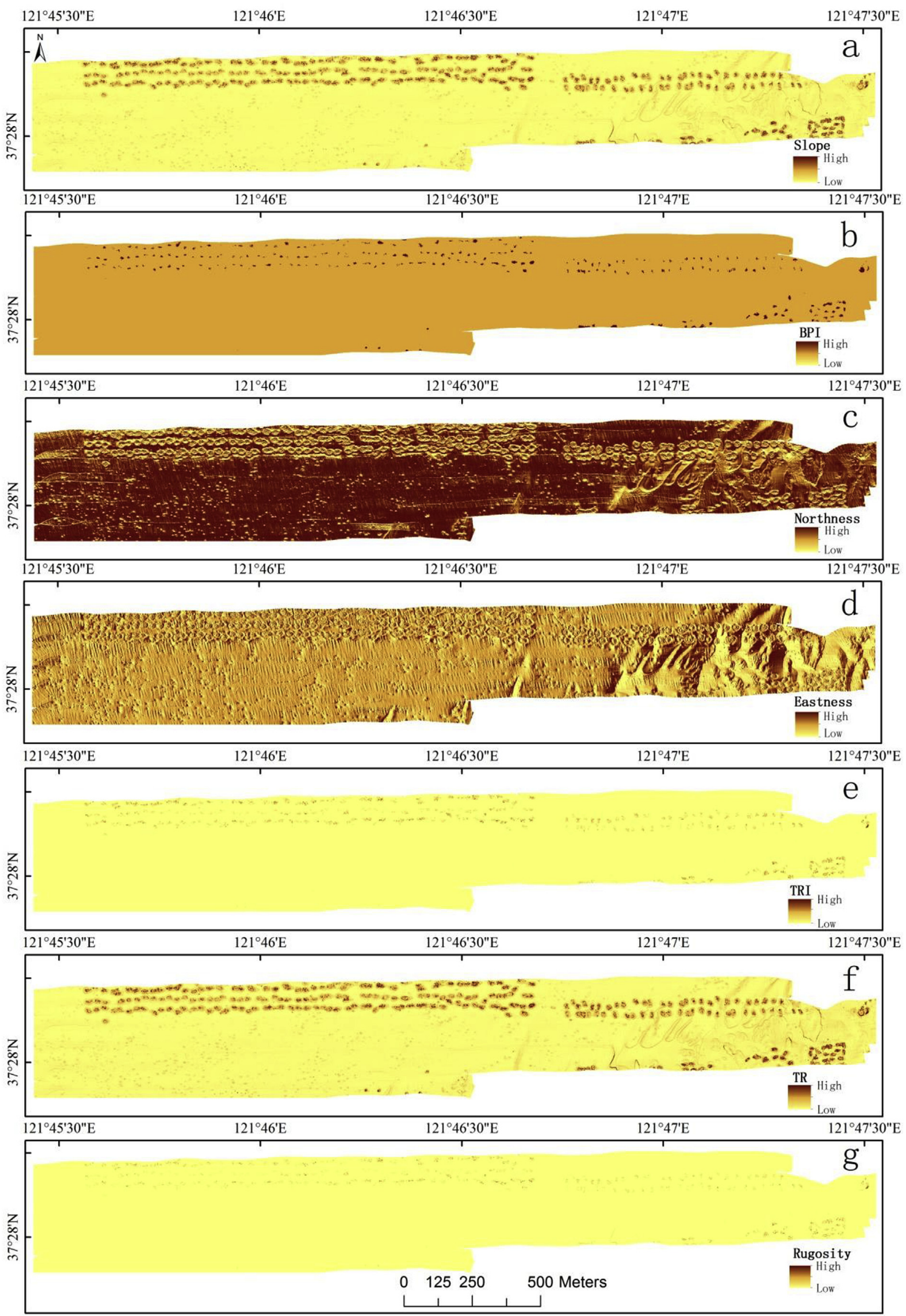

Fig. 4. Multibeam-derived data layers used in the classification: (a) Slope, (b) BPI, (c) Northness, (d) Eastness, (e) TRI, (f) TR and (g) Rugosity. 
Table 2

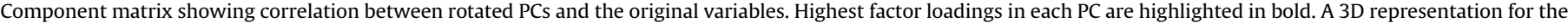
first there PCs is illustrated in Fig. 5.

\begin{tabular}{|c|c|c|c|c|c|c|c|c|c|}
\hline Variables & PC1 & PC2 & PC3 & PC4 & PC5 & PC6 & PC7 & PC8 & PC9 \\
\hline Backscatter & 0.2150 & -0.5915 & -0.0800 & 0.2421 & 0.0594 & 0.6720 & 0.1893 & 0.2186 & -0.0073 \\
\hline Bathymetry & -0.0998 & 0.6595 & -0.1432 & -0.2853 & -0.1409 & 0.6273 & 0.1640 & 0.1141 & 0.0043 \\
\hline Slope & 0.4872 & 0.0736 & 0.0038 & 0.0279 & -0.2062 & 0.0690 & -0.2588 & -0.2158 & 0.7718 \\
\hline BPI & 0.2666 & 0.2059 & -0.0229 & -0.0211 & 0.9190 & 0.0597 & -0.1894 & 0.0404 & 0.0009 \\
\hline Northness & -0.1866 & 0.3312 & -0.0181 & 0.9172 & -0.0056 & 0.0595 & -0.0315 & -0.0966 & 0.0088 \\
\hline Eastness & 0.0055 & 0.0588 & 0.9860 & -0.0053 & 0.0060 & 0.1474 & 0.0361 & 0.0344 & -0.0036 \\
\hline TRI & 0.4198 & 0.1430 & -0.0016 & 0.0701 & 0.0434 & -0.2494 & 0.8524 & -0.0871 & 0.0142 \\
\hline TR & 0.4774 & 0.0541 & -0.0011 & 0.0073 & -0.1845 & 0.1460 & -0.2382 & -0.5439 & -0.6010 \\
\hline Rugosity & 0.4432 & 0.1757 & -0.0010 & 0.1123 & -0.2315 & -0.1943 & -0.2210 & 0.7597 & -0.2068 \\
\hline Eigenvalues & 3.7689 & 1.5188 & 1.0117 & 0.8295 & 0.7716 & 0.4718 & 0.3692 & 0.2135 & 0.0450 \\
\hline
\end{tabular}

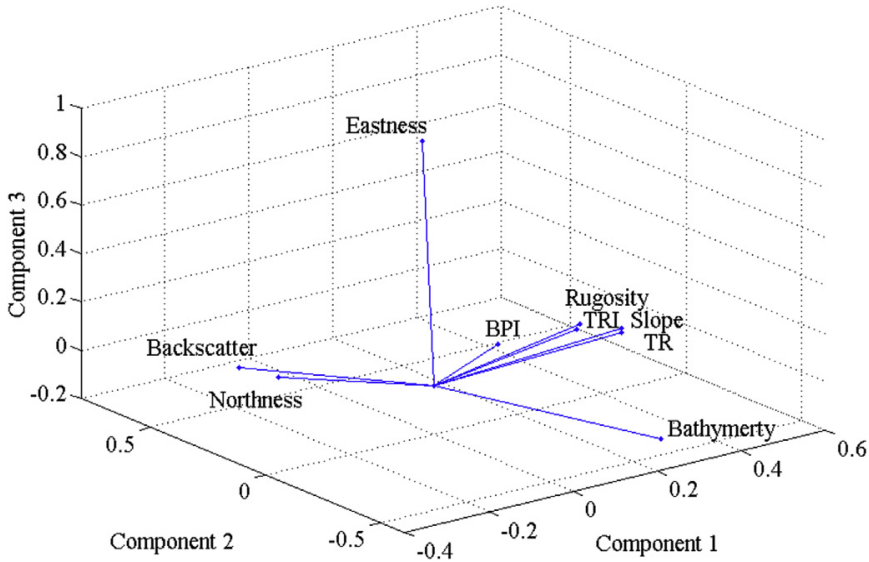

Fig. 5. 3D representation of the first three PCs and coefficients of each variable. The plot illustrates which variables are driving the PCs. The longest arrow in the plot represents the most prominent variable in the PCs. The distances between arrows describe their correlation, the closer the arrows, the more correlated they are.

the north, and a small portion of the ARs were in the south. This class consisted of different types of ARs and was characterized by strong acoustic return signals from the backscatter image (Fig. 8).

The ARs on the seafloor could be classified into two categories: concrete reef units and stones mined from hills, which had been verified by local fisheries management authorities and scuba diving investigation (Fig. 6c and d and Fig. 8). These ARs exhibited high acoustic reflectivity on the backscatter images compared with the darker areas of sand and mud sediments (Fig. 2b). According to the raw MBES data and diving survey, it is clear that ARs in the study area were mostly constructed of stones while concrete reef units accounted for only a small part (Fig. $6 c$ and d and Fig. 8). Underwater optical video observations around the ARs showed that there was a high biomass of large benthic organisms such as jacopever, crab, and sea cucumber (Fig. 6e and f). Such key species could offer potential for evaluating AR effects. It is important to note that the number of benthic organisms around the concrete reef units was much larger than that of the stones reef (Fig. $6 \mathrm{c}$ and e). This was likely to be related to the shape and structure provided by different types of ARs. The seabed around ARs was dominated by unconsolidated deposits of mud and sand (Fig. 6a and b, Table 3). The southern part of the study area, near the shore, was sandy bottom, and the substrate gradually became muddy with water depth deepening northward.

\section{Discussion}

\subsection{Echo-sounder dataset mining for ARs}

In this study, we used MBES data and their derived variables to map ARs and surrounding habitats. Accurate delineate of benthic habitat is dependent on the quality of acoustic data (Brown and Blondel, 2009). During MBES survey, systematic disturbance often arise because of waves, swells, and other sea surface variation. Additionally, artifacts in bathymetry and backscatter data are also introduced when the echo sounder movements cannot be sufficiently compensated (Diesing et al., 2014). In this study, the bathymetry and backscatter grids were aggregated to a spatial resolution of $0.5 \mathrm{~m}$ based on the quality of original data. In this study, the vessel speed of 6 knots (i.e. multibeam scanning speed) could result in slight vibration of the transducer. If the raw data was processed into a higher spatial resolution (e.g. $0.25 \mathrm{~m}$ ), there was a marked "jitter" phenomenon as shown in Fig. 9. However, when the raw data was processed into $0.5 \mathrm{~m}$ resolution, the "jitter" data can be "smoothed out". Therefore, acoustic data at $0.5 \mathrm{~m}$ resolution was used in the classification process.

Despite potential sources of error and the pixel resolution, previous studies have shown that bathymetry, backscatter and derived topographic variables from multibeam systems capable of estimating geophysical information related to properties of benthic substrata (Brown et al., 2012; Dartnell and Gardner, 2004; Micallef et al., 2007; Roberts et al., 2005). For instance, slope is an important factor in determining benthic habitat (Wilson et al., 2007). Our study area is located in a depositional environment with gradual slope (Fig. 2a). The frequency distribution of slope gradient data is unimodal and highly positively skewed (Fig. 3d). The point of inflection occurs at a slope gradient value of about $5^{\circ}$, which could separate the AR seafloor from flat bottom. This is similar to the method used by Micallef et al. (2007) to classify seabed into flat and sloping zones. Many different types of variables based on MBES data have been employed by researchers to characterize the topographic features and map various types of benthic habitats. Roberts et al. (2005) produced seafloor maps based on acoustic classification using combining bathymetry, slope and backscatter images. Hill et al. (2014) used 9 topographic variables and 6 textural variables to predict the distribution of reef biota. In our study, 9 variables were derived from MBES data and successfully utilized to map ARs and surrounding habitats. The result clearly illustrated the location, distribution, and subsidence of ARs from the detailed bathymetry data. Our approach was efficient for calculating the coverage of ARs on the seabed, estimating sediments types around ARs, and producing digital thematic maps. These information can assist the managers to make a reasonable evaluation on the effectiveness of ARs combined with biological data (e.g. abundance and biomass) and abiotic data such as temperature, $\mathrm{pH}$, oxygen, and salinity (Punzo et al., 2015; Schygulla and Peine, 2013). In addition, this can provide reference for the future construction of ARs and help local managers to better monitor coastal waters.

The original bathymetry had been drastically changed as a result of the deployment of reef units and thus influenced the local coastal currents (Schygulla and Peine, 2013). On average, the relative 


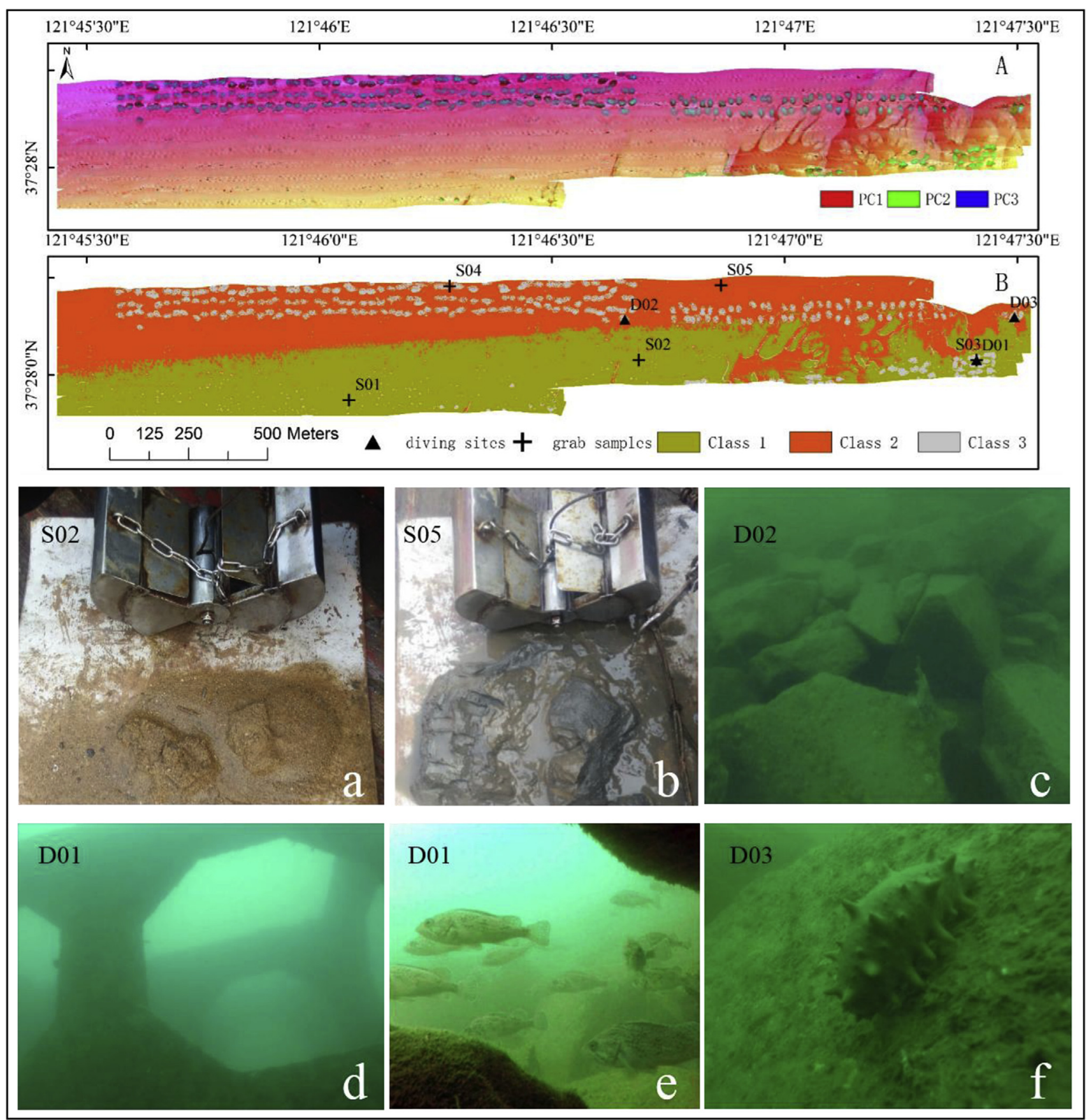

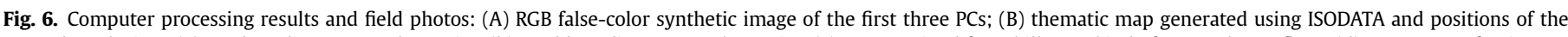

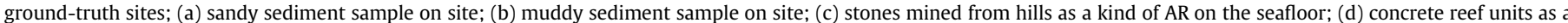

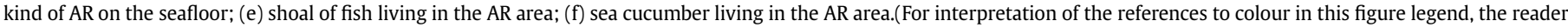
is referred to the web version of this article.)

height of ARs on the seafloor was more than $1 \mathrm{~m}$ in our study area. ARs can undergo geophysical processes, and the deepening or scouring effects (Shyue and Yang, 2002) around ARs can be detected using bathymetric maps and profiles. As shown in Fig. 3c, the deepening area with a maximum height of approximately $0.4 \mathrm{~m}$ indicated the presence of a scouring process around ARs within a radius of $5 \mathrm{~m}$. The construction of ARs on the seabed leads to changes in local hydrodynamics. Specifically, ARs increase the intensity of turbulence and the flow rate outside their perimeters (Schygulla and Peine, 2013). Baynes and Szmant (1989) showed the significance of the current flow around a wreck AR for sessile benthic community. The altered relief and hydrodynamic conditions of the reef unit arrangements can support regions that are conducive to colonization by other species due to the reduced nearbottom flow or free stream velocity. Similarly, Giusti et al. (2014) found that the corals prefers to live in sites with rocks oriented to the northeast due to variation of the underlying velocity caused by reefs in the South Tyrrhenian Sea. Because of increased surface area provided by ARs, ecosystem function as spawning and nursery ground improved in the vicinity of the deployed reef units. 


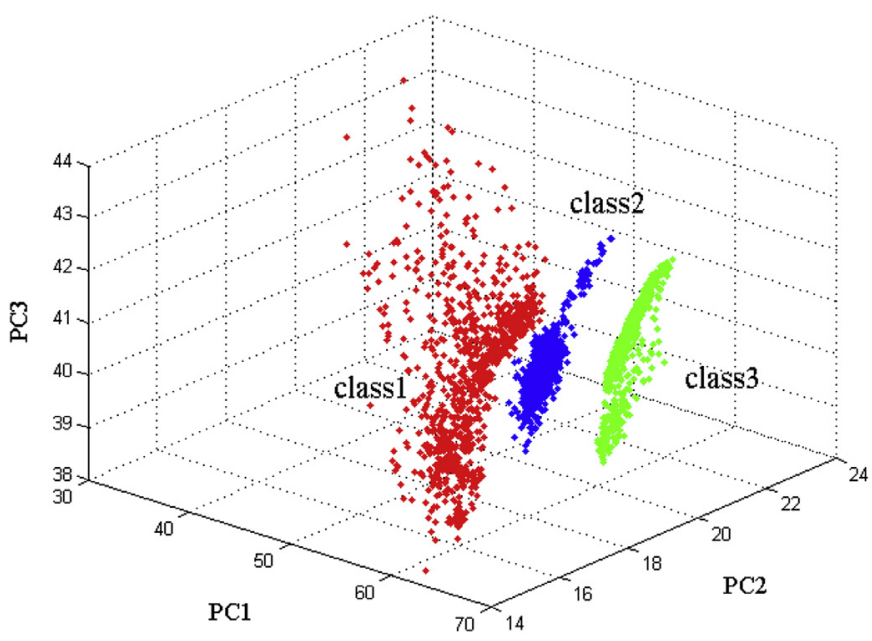

Fig. 7. 3D representation of correspondence between the ISODATA classes and three PCs.
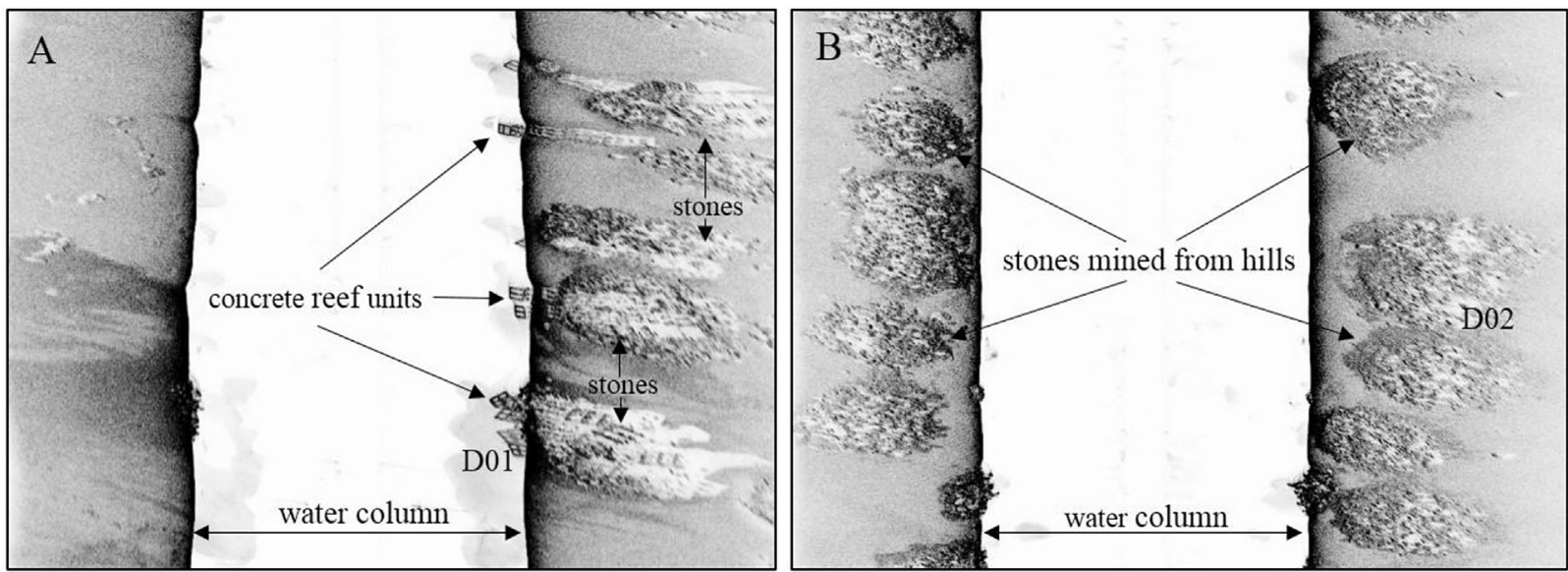

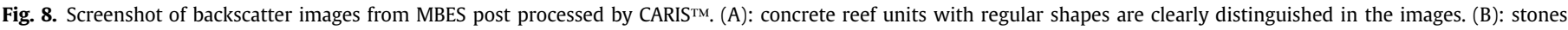
mined from hills are irregularly scattered on the seafloor.

Table 3

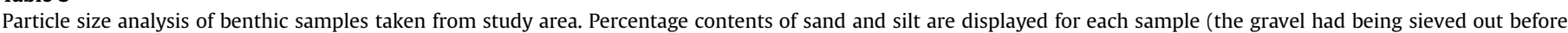

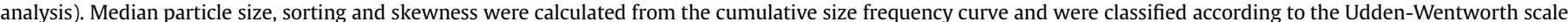
(analyzed using GRADISTAT developed by Blott and Pye (2001)).

\begin{tabular}{|c|c|c|c|c|c|}
\hline Sample & S01 & S02 & S03 & S04 & S05 \\
\hline$\%$ Very coarse sand & $0.0 \%$ & $0.0 \%$ & $19.4 \%$ & $0.0 \%$ & $0.0 \%$ \\
\hline$\%$ Coarse sand & $0.0 \%$ & $0.0 \%$ & $52.1 \%$ & $0.1 \%$ & $0.1 \%$ \\
\hline \% Medium sand & $25.7 \%$ & $26.7 \%$ & $23.0 \%$ & $2.8 \%$ & $15.4 \%$ \\
\hline$\%$ Fine sand & $67.3 \%$ & $63.8 \%$ & $3.9 \%$ & $6.9 \%$ & $26.9 \%$ \\
\hline \% Very fine sand & $5.1 \%$ & $5.1 \%$ & $1.5 \%$ & $17.5 \%$ & $16.5 \%$ \\
\hline \% Very coarse silt & $0.0 \%$ & $0.4 \%$ & $0.0 \%$ & $16.5 \%$ & $9.6 \%$ \\
\hline$\%$ Coarse silt & $0.0 \%$ & $1.6 \%$ & $0.0 \%$ & $12.4 \%$ & $6.1 \%$ \\
\hline \% Medium silt & $0.2 \%$ & $0.5 \%$ & $0.0 \%$ & $14.4 \%$ & $6.6 \%$ \\
\hline$\%$ Fine silt & $1.0 \%$ & $1.1 \%$ & $0.0 \%$ & $13.9 \%$ & $7.5 \%$ \\
\hline$\%$ Very fine silt & $0.6 \%$ & $0.7 \%$ & $0.0 \%$ & $8.6 \%$ & $5.6 \%$ \\
\hline \% Clay & $0.1 \%$ & $0.0 \%$ & $0.0 \%$ & $6.8 \%$ & $5.6 \%$ \\
\hline Median (phi) & 2.306 & 2.310 & 0.615 & 5.616 & 4.258 \\
\hline Sorting (phi) & 0.464 & 0.512 & 0.740 & 2.190 & 2.496 \\
\hline Skewness (phi) & 0.036 & 0.079 & 0.128 & 0.100 & 0.499 \\
\hline Kurtosis (phi) & 0.999 & 1.086 & 1.070 & 0.837 & 0.843 \\
\hline Classification & Fine sand & Fine sand & Coarse sand & Coarse silt & Very coarse silt \\
\hline
\end{tabular}

Increasing amount of particulate organic matter has become available and has led to the appearance of increased population of benthic organisms, which are valuable for aquaculture. Earlier research has confirmed the importance of the ARs as a food supplier and hot spot for secondary production (Cresson et al., 2014a). This also concurs with the findings of Hill et al. (2014), who showed the textural complexity of rocky reefs influences the distribution of sessile fauna.

Though the results show that MBES can be used effectively to distinguish ARs from the soft sediments, 2 different types of ARs that are located in close proximity were not separated from each other at this stage of the trials. Future work is warranted to improve the classification algorithm to distinguish between different types of ARs that are in close proximity. The possible solutions include increased spatial resolution from low-speed scanning and incorporation of different acoustic frequencies. In addition, the different benthic organism populations observed in different types of ARs indicated that the shape and structure of ARs may have impacts for biological communities living on them and their productivity. This phenomenon was highlighted by Punzo et al. (2015), who found that aggregation effect of ARs on fish assemblages is related to the 

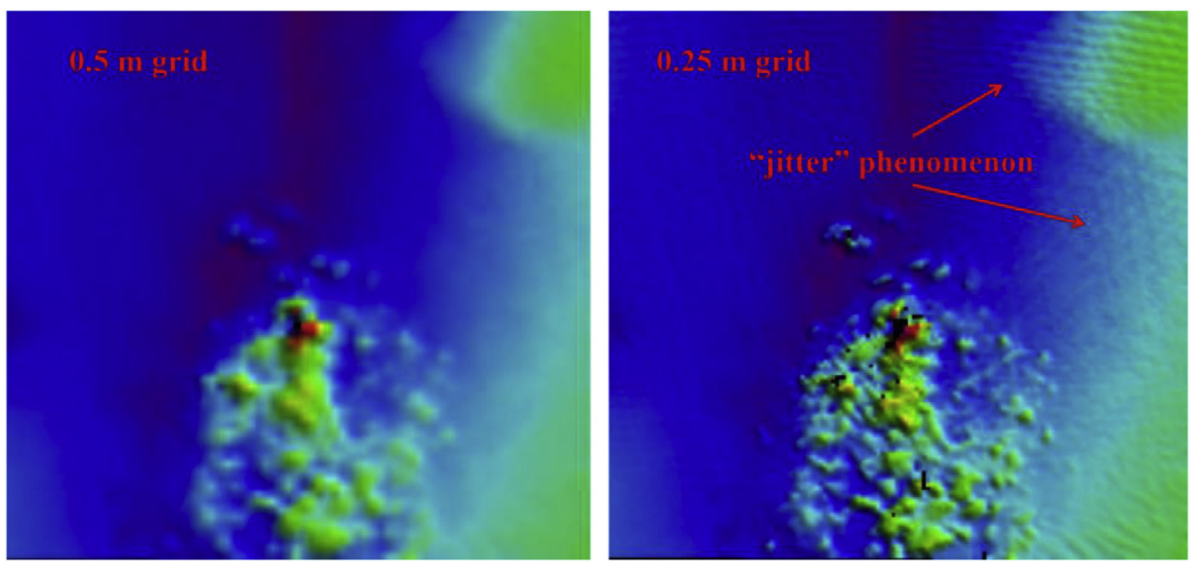

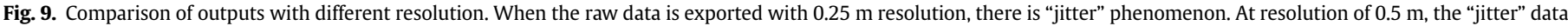
can be "smoothed out".

providing suitable habitats, and the complexity of reef structures (size of modules, density of installed modules etc.) is an important factor for the aggregation (Gokce, 2015). Overall, the MBES observation provided a technically feasible approach for in-situ monitoring of morphological and hydrodynamic variations and evaluating the habitat health for benthic organisms in the vicinity of ARs.

\subsection{Automated acoustic classification}

Automated approaches have advantages over the conventional time-consuming manual interpretation methods as they remove the subjectivity of boundary placement between neighbouring acoustic facies and provide an objective and reproducible method (Brown and Collier, 2008). Although several automated classification methods have been developed in the past for mapping seafloor habitat with MBES data (Brown et al., 2012; Hasan et al., 2012; McGonigle et al., 2009), standard approach applicable for all habitat types does not exist. The supervised classification methods require sufficient training dataset obtained from in-situ sampling to "guide" the classification (Brown et al., 2012; Diesing et al., 2014). Our study area is relatively small $\left(1.15 \mathrm{~km}^{2}\right)$ while large scale ARs on the seabed resulted in highly complex local geometry. The supervised classification approach is not applicable given the limited number of samples. In comparison, unsupervised classification is capable of distinguishing between different classes of benthic habitat with optimum number of clusters (Stephens and Diesing, 2014). It is successfully applied in our study to delineate 3 dominant types of benthic environment (i.e., gently sloped sandy sediment, flat muddy sediment, and rugged ARs). The MBES observations provided sufficient detail to distinguish between concrete and rocky types of ARs although the difference was not captured in the unsupervised classification scheme.

Our study demonstrates the applicability of ISODATA algorithm using MBES in automatic classification of large scale ARs. The ISODATA clustering method can greatly reduce the likelihood of operator bias, reduce the time and cost of data interpretation, and ensure the consistency of the classification results (Ierodiaconou et al., 2011). Our approach is implemented in a GIS environment, which allows further spatial analyses and algorithm development. The main benefit of ISODATA is that it combines multiple variables into a simplified comprehensive overview of the interested area. However, the method requires prior experience of the study area, which is essential for the interpretation of acoustically derived classes. It has been stated that the development of a statistically robust method to direct ground-truth effort for unsupervised classification is largely elusive (McGonigle et al., 2009). Expert visual interpretation based on sidescan sonar imagery should be used to evaluate the performance of the clustering technique (Ismail et al., 2015). Due to the lack of detailed preliminary geomorphology survey in the study area, the accuracy of classification results can only be qualitatively validated by multibeam raw data and a small set of field sampled data. The concordance of classification results with sediment samples and dive observations provides credibility to the performance of the ISODATA method in segmenting the seafloor in areas with ARs.

We believe the combination of MBES survey and semiautomatic classification algorithm provides an efficient and costeffective approach for providing the benthic habitat information much needed by costal managers and aquaculture industries. It should be noted that the quantitative classification and mapping approach developed in this small scale pilot study need to be further verified in other coastal regions with different physical and biological settings. Further studies are warranted to develop an upscaling method to extend the quantitative method from small testing regions to large coastal regions.

\section{Conclusions}

This research demonstrated the use of the ISODATA method to produce a benthic classification map of large-scale ARs in shallow water using MBES data. The approach provides an efficient and cost-effective technique for mapping and managing large ARs for aquaculture and fisheries that formerly lacked benthic habitat information. The technology we employed is transferable to other benthic habitat characterization efforts, where efficient management is inhibited because of a lack of comprehensive spatial information. The quantitative characterization of MBES data for largescale AR mapping is a developing field that warrants further research and exploration of massive multibeam data mining and intelligent classification algorithms.

\section{Acknowledgments}

This work was financially supported by grants from the National Key Basic Research Program of China (973) (No.2015CB453301), the Strategic Priority Research Program of the Chinese Academy of Sciences (No. XDA11020305), and the Key Deployment Project of Chinese Academy of Sciences (No. KZZD-EW-14). 
Appendix A. Supplementary data

Supplementary data related to this article can be found at http:// dx.doi.org/10.1016/j.ecss.2016.12.001.

\section{References}

Adediran, A.O., Parcharidis, I., Poscolieri, M., Pavlopoulos, K., 2004. Computerassisted discrimination of morphological units on north-central Crete (Greece) by applying multivariate statistics to local relief gradients. Geomorphology 58, 357-370.

Ball, G.H., Hall, D.J., 1967. A clustering technique for summarizing multivariate data. Behav. Sci. 12, 153-155.

Baynes, T.W., Szmant, A.M., 1989. Effect of current on the sessile benthic community structure of an artificial reef. Bull. Mar. Sci. 44, 545-566.

Blott, S.J., Pye, K., 2001. GRADISTAT: a grain size distribution and statistics package for the analysis of unconsolidated sediments. Earth Surf. Process Landf 26 1237-1248.

Bortone, S.A., 2015. CARAH (International conference on artificial reefs and related aquatic habitats): an historical perspective of accomplishments. J. Appl. Ichthyol. 31, 3-14.

Brochier, T., Auger, P., Thiam, N., Sow, M., Diouf, S., Sloterdijk, H., Brehmer, P., 2015 Implementation of artificial habitats: inside or outside the marine protected areas? Insights from a mathematical approach. Ecol. Model 297, 98-106.

Brown, C.J., Blondel, P., 2009. Developments in the application of multibeam sonar backscatter for seafloor habitat mapping. Appl. Acoust. 70, 1242-1247.

Brown, C.J., Collier, J.S., 2008. Mapping benthic habitat in regions of gradational substrata: an automated approach utilising geophysical, geological, and biological relationships. Estuar. Coast. Shelf Sci. 78, 203-214.

Brown, C.J., Sameoto, J.A., Smith, S.J., 2012. Multiple methods, maps, and management applications: purpose made seafloor maps in support of ocean management. J. Sea Res. 72, 1-13.

Brown, C.J., Smith, S.J., Lawton, P., Anderson, J.T., 2011. Benthic habitat mapping: a review of progress towards improved understanding of the spatial ecology of the seafloor using acoustic techniques. Estuar. Coast. Shelf Sci. 92, 502-520.

Cresson, P., Ruitton, S., Harmelin-Vivien, M., 2014a. Artificial reefs do increase secondary biomass production: mechanisms evidenced by stable isotopes. Mar Ecol. Prog. Ser. 509, 15-26.

Cresson, P. Ruitton, S., Ourgaud, M., Harmelin-Vivien, M., 2014b. Contrasting perception of fish trophic level from stomach content and stable isotope analyses: a Mediterranean artificial reef experience. J. Exp. Mar. Biol. Ecol. 452 54-62.

Dartnell, P., Gardner, J.V., 2004. Predicting seafloor facies from multibeam bathymetry and backscatter data. Photogramm. Eng. Remote Sens. 70, 1081-1091.

Diesing, M., Green, S.L., Stephens, D., Lark, R.M., Stewart, H.A., Dove, D., 2014 Mapping seabed sediments: comparison of manual, geostatistical, object-based image analysis and machine learning approaches. Cont. Shelf Res. 84, 107-119.

Falace, A., Bressan, G., 2002. A qualitative and quantitative analysis of the evolution of macroalgal vegetation on an artificial reef with anti-grazing nets (LoanoLigurian Sea). ICES J. Mar. Sci. 59, 150-156.

Giusti, M., Innocenti, C., Canese, S., 2014. Predicting suitable habitat for the gold coral savalia savaglia (Bertoloni, 1819) (Cnidaria, Zoantharia) in the south Tyrrhenian sea. Cont. Shelf Res. 81, 19-28.

Gokce, G., 2015. Design, deployment and fish assemblages of artificial reefs in Iskenderun Bay, Turkey: initial experiences. J. Appl. Ichthyol. 31, 35-40.

Harper, S.J.M., Bates, C.R., Guzman, H.M., Mair, J.M., 2010. Acoustic mapping of fish aggregation areas to improve fisheries management in Las Perlas Archipelago, Pacific Panama. Ocean. Coast. Manage 53, 615-623.

Hasan, R.C., Ierodiaconou, D., Monk, J., 2012. Evaluation of four supervised learning methods for benthic habitat mapping using backscatter from multi-beam sonar. Remote Sens. 4, 3427-3443.

Hill, N.A., Lucieer, V., Barrett, N.S., Anderson, T.J., Williams, S.B., 2014. Filling the gaps: predicting the distribution of temperate reef biota using high resolution biological and acoustic data. Estuar. Coast. Shelf Sci. 147, 137-147.

Huang, Z., Siwabessy, J., Nichol, S.L., Brooke, B.P., 2014. Predictive mapping of seabed substrata using high-resolution multibeam sonar data: a case study from a shelf with complex geomorphology. Mar. Geol. 357, 37-52.

Ierodiaconou, D., Monk, J., Rattray, A., Laurenson, L., Versace, V.L., 2011. Comparison of automated classification techniques for predicting benthic biological communities using hydroacoustics and video observations. Cont. Shelf Res. 31 S28-S38.

Ismail, K., Huvenne, V.A.I., Masson, D.G., 2015. Objective automated classification technique for marine landscape mapping in submarine canyons. Mar. Geol. 362 $17-32$.
Jones, E., Caprarelli, G., Mills, F.P., Doran, B., Clarke, I., 2014. An alternative approach to mapping Thermophysical units from martian Thermal Inertia and albedo data using a combination of unsupervised classification techniques. Remote Sens. 6, 5184-5237.

Kang, M., Nakamura, T., Hamano, A., 2011. A methodology for acoustic and geospatial analysis of diverse artificial-reef datasets. ICES J. Mar. Sci. 68, 2210-2221.

Lundblad, E.R., Wright, D.J., Miller, I., Larkin, E.M., Rinehart, R., Naar, D.F., Donahue, B.T., Anderson, S.M., Battista, T., 2006. A benthic terrain classification scheme for American Samoa. Mar. Geod. 29, 89-111.

McGonigle, C., Brown, C., Quinn, R., Grabowski, I., 2009. Evaluation of image-based multibeam sonar backscatter classification for benthic habitat discrimination and mapping at Stanton Banks, UK. Estuar. Coast. Shelf Sci. 81, 423-437.

Memarsadeghi, N., Mount, D.M., Netanyahu, N.S., Moigne, J., 2007. A fast implementation of the ISODATA clustering algorithm. Int. J. Comput. Geom. Appl. 17, $\underline{71-103 .}$

Micallef, A., Berndt, C., Masson, D.G., Stow, D.A.V., 2007. A technique for the morphological characterization of submarine landscapes as exemplified by debris flows of the Storegga Slide. J. Geophys. Res. 112, 488-501.

Micallef, A., Le Bas, T.P., Huvenne, V.A.I., Blondel, P., Hühnerbach, V., Deidun, A. 2012. A multi-method approach for benthic habitat mapping of shallow coastal areas with high-resolution multibeam data. Cont. Shelf Res. 39-40, 14-26.

Moustier, C.D., Matsumoto, H., 1993. Seafloor acoustic remote sensing with multibeam echo-sounders and bathymetric sidescan sonar systems. Mar. Geophys. Res. 15, 27-42.

Muller, R.D., Eagles, S., 2007. Mapping seabed geology by ground-truthed textural image/neural network classification of acoustic backscatter mosaics. Math. Geol. 39, 575-592.

Pickering, H., Whitmarsh, D., 1997. Artificial reefs and fisheries: a review of the 'attraction versus production' debate, the influence of design and its significance for policy. Fish. Res. 31, 39-59.

Pickrill, R.A., Todd, B.J., 2003. The multiple roles of acoustic mapping in integrated ocean management, Canadian Atlantic continental margin. Ocean. Coast. Manage 46, 601-614.

Punzo, E., Malaspina, S., Domenichetti, F., Polidori, P., Scarcella, G., Fabi, G., 2015 Fish detection around offshore artificial structures: preliminary results from hydroacoustics and fishing surveys. J. Appl. Ichthyol. 31, 48-59.

Relini, M., Torchia, G., Relini, G., 1994. Seasonal variation of fish assemblages in the Loano artificial reef (Ligurian Sea Northwestern-Mediterranean). Bull. Mar. Sci. 55, 401-417.

Roberts, J.M., Brown, C.J., Long, D., Bates, C.R., 2005. Acoustic mapping using a multibeam echosounder reveals cold-water coral reefs and surrounding habitats. Coral Reefs 24, 654-669.

Santos, L.N.D., Brotto, D.S., Zalmon, I.R., 2010. Fish responses to increasing distance from artificial reefs on the Southeastern Brazilian Coast. J. Exp. Mar. Biol. Ecol. 386, 54-60.

Schygulla, C., Peine, F., 2013. Nienhagen reef: abiotic boundary conditions at a large Brackish water artificial reef in the Baltic sea. J. Coast. Res. 29, 478-486.

Seaman, W., Jensen, A.C., 2000. Purposes and Practices of Artificial Reef Evaluation, Crc Press-Taylor \& Francis Group, Boca Raton.

Shyue, S.W., Yang, K.C., 2002. Investigating terrain changes around artificial reefs by using a multi-beam echosounder. ICES J. Mar. Sci. 59, S338-S342.

Stephens, D., Diesing, M., 2014. A comparison of supervised classification methods for the prediction of substrate type using multibeam acoustic and legacy grainsize data. PLoS One 9, e93950.

Tessier, A., Blouet, S., Lenfant, P., Verdoit-Jarraya, M., Dalias, N., 2014. A case study of artificial reefs as a potential tool for maintaining artisanal fisheries in the French Mediterranean Sea. Aquat. Biol. 20, 255-272.

Wilson, K.D.P., Leung, A.W.Y., Kennish, R., 2002. Restoration of Hong Kong fisheries through deployment of artificial reefs in marine protected areas. ICES J. Mar. Sci, 59, S157-S163.

Wilson, M.F.J., O'Connell, B., Brown, C., Guinan, J.C., Grehan, A.J., 2007. Multiscale terrain analysis of multibeam bathymetry data for habitat mapping on the continental slope. Mar. Geod. 30, 3-35.

Wu, X., Kumar, V., Quinlan, J.R., Ghosh, J., Yang, Q., Motoda, H., Mclachlan, G.J., Ng, A., Liu, B., Yu, P.S., 2007. Top 10 algorithms in data mining. Knowl. Inf. Syst. $14,1-37$.

Yoon, H.-S., Kim, D., Na, W.-B., 2016. Estimation of effective usable and burial volumes of artificial reefs and the prediction of cost-effective management. Ocean. Coast. Manage 120, 135-147.

Yuan, D., Zhu, J., Li, C., Hu, D., 2008. Cross-shelf circulation in the Yellow and East China Seas indicated by MODIS satellite observations. J. Mar. Syst. 70, 134-149.

Zhang, S.W., Wang, Q.Y., Lü, Y., Cui, H., Yuan, Y.L., 2008. Observation of the seasonal evolution of the Yellow sea cold water mass in 1996-1998. Cont. Shelf Res. 28, 442-457. 